\title{
Analysis on the Effect of Capacitor Banks Operation towards Total Harmonic Distortions (THD) in Distribution Network Test System
}

\author{
Dalila M.S. , Zaris I.M.Y., Nasarudin A., Faridah H. \\ School of Electrical Engineering, Faculty of Engineering, Universiti Teknologi Malaysia, 81310 Johor \\ Bahru, Johor, Malaysia \\ *Corresponding author: dalila@utm.my
}

\author{
Article History \\ Received: Jan 09, 2018 Received in revised form: Nov 14, 2018 Accepted: Nov 18, 2018 Published: Nov 30, 2018
}

\begin{abstract}
This paper purposely to examine and analyse the impact of the distribution capacitors banks operation to the transition of total harmonic distortion (THD) level in distribution network system. The main advantage of this work is the simplicity algorithm of the method and the system being analysed using free access open software which is known as electric power distribution system simulator (OpenDSS). In this paper, the harmonic current spectrum which is collected from the commercial site was injected to a node point on IEEE13 bus in order to provide the initial measurement of THD for the network. The proper sizing of the capacitors banks has been set and being deactivated and activated throughout the network to see the transistion in the THD level in the system. The results were achieved by simulation of the data on the configured IEEE13 bus. The simulation work was done by using the combination of C++ source codes, OpenDSS and Microsoft Excel software. From the output results, the THD current has increased up to two times from the initial value in certain phases and for the THD voltage, the THD has increased up to three times from its initial value in all phases.
\end{abstract}

Keywords: Distribution capacitors; Resonance; Total Harmonic Distortion (THD); Harmonics; Power Factor

\subsection{INTRODUCTION}

In any operation of power distribution network, it requires proper equipment configuration for the network in a way to assure the good quality of its performance. The placement of capacitors banks is one of the normal configuration in normal design of electrical power distribution. Generally, the purpose of the capacitors is to significantly reducing power loss, enhancing the voltage stability, compensating reactive power and correcting the power factor within the system [1]. The major operation of the capacitors banks is to correct and improve the power factor to be remained close to unity. But despite to its function, the operation of these capacitors can give displeasure impacts and produce numerous problems such as transient, nuisance tripping and most importantly magnifying the total harmonic distortions (THD) which already have existed in the network system even right before the capacitors being connected to the system. The THD could be excessively magnified due to the nature operation of the capacitors that can produce resonance condition especially when they combined with the short-circuit impedance [2-4]. In this paper, the case study will show the how the operation of the capacitors banks has increased the total harmonic distortion to the extent that can seriously harm the whole network system. The main advantage of this work was the accessibility of the network configuration which available in the Opendss software. Other than that, the application of the real data from commercial building enable the network to be analysed under real condition of harmonic current spectrum. Hence, the output results be able to provide an analysis based on real scenarios of a network system. At the end of this paper, an analysis on the impact from the operation of the capacitor banks towards the increment in total harmonic distortion is expected to prove the hypothesis. 


\subsection{METHODOLOGY}

The IEEE13 node buses schematic diagram as in the Figure 1 has been chosen to implement the case study for this work. Each of node bus on the schematic were either in single phase $(1 \varnothing)$ or in three phase $(3 \emptyset)$ configuration system setting. As shown in the figure, there were two units of capacitor banks been setup at 611 node bus and also at the 675 node bus. These alignments were purposely to provide a series connection between the capacitors and the harmonic current spectrums source. Thus from there, the effect of series resonance could be occurred which led to the magnification or transition in the harmonic distortion.

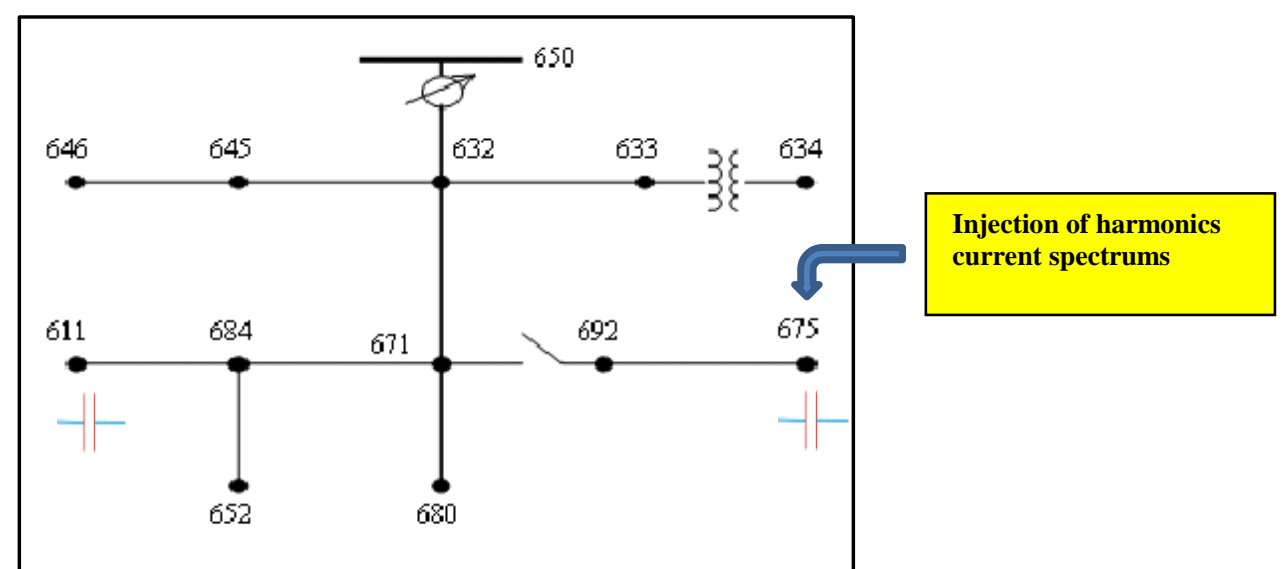

Figure 1. The injection of harmonics current spectrums at node 675 on IEEE13 bus test system

The idea of this work was to inject the harmonic current spectrums on the selected node bus before and after the capacitor banks being connected to the system. The purpose was to prove the hypothesis that the operation of both capacitor banks could give impact to the existed harmonic distortion level in the network system. To be clarified, the 611 node bus was setup for $1 \emptyset$ system meanwhile the 675 node bus was setup for $3 \emptyset$ system. The harmonic current spectrums were collected from the commercial building for one-week period started from 10 February 2010 until 16 February 2010. Then, the harmonic spectrums on 13 February 2010 were chosen to be injected to the 675 node bus network system. The selection of the harmonic spectrums on that particular date was simply because it was on working day hours and the harmonic currents were expected to be generated at higher value.

\subsection{Size of capacitor banks}

As for the capacitor banks, their size has been setup to match with the rated power for each 611 node bus and 675 node bus as can be seen in Table 1. The size of the capacitor banks was determined by the consecutive formula below:

- Power factor

$$
\text { - } \cos \theta=\frac{\text { Real power, } P}{\text { Apparent power, } S}
$$

- Size of capacitor, Qc

$$
\text { - } Q c=P \tan \theta
$$


Table 1. The size of the capacitor banks that have been set up for the node buses

\begin{tabular}{|c|c|c|c|c|}
\hline Node & V line, $\mathrm{V}(\mathrm{kV})$ & Real power, $\mathrm{P}(\mathrm{kW})$ & $\begin{array}{c}\text { Rated reactive } \\
\text { power, Qr }(\mathrm{kVar})\end{array}$ & $\begin{array}{c}\text { Cap banks size, Qc } \\
(\mathrm{kVar})\end{array}$ \\
\hline $675 \mathrm{a}$ & 4.16 & 485.0 & 190.0 & 191.73 \\
\hline $675 \mathrm{~b}$ & 4.16 & 68.0 & 60.0 & 18.9 \\
\hline $675 \mathrm{c}$ & 4.16 & 290.0 & 212.0 & 51.5 \\
\hline 611 & 2.4 & 170.0 & 80 & 109.32 \\
\hline
\end{tabular}

$*$ The subscripts $a, b$, and c represent phase $a$, phase $b$ and phase $\mathrm{c}$ for the $3 \emptyset$ system at 675 node bus.

\subsection{Total of harmonic distortions and harmonic order}

In the perspective of harmonic distortion analysis, the following formulas of total harmonic distortion for current and voltage (THDi and THDv) respectively were used in the calculation.

- Total current harmonic distortion, $T H D i$

$$
\text { - } T H D i=\frac{\sqrt{\sum I^{2}}}{I_{1}}
$$

- Total voltage harmonic distortion, $T H D v$

$$
\text { - } T H D v=\frac{\sqrt{\sum V n^{2}}}{V_{1}}
$$

As mentioned earlier, the connection between the capacitor banks and harmonic current spectrums source in series would induces a resonance which then became the main factor for the harmonic distortion to be magnified. Thus for this paper, in order to determine which harmonic order that has being magnified, the formula of resonance frequency shown below was used.

- Resonance frequency, fr

$$
\text { - } f r=f s \sqrt{\frac{S s c}{Q r}}
$$

Where,

- $f s=$ the system frequency

- $\quad S s c=$ the short circuit power $(\mathrm{kVA})$ at the point where the capacitor is to be connected

- $Q r=$ the rated reactive power

- Harmonic order, $\mathrm{H}$

$$
H=\sqrt{\frac{f r}{f s}}
$$




\subsection{Related international standard}

In any research work, the output results must be referred to related international standard in order to see the compliance of the results to the standard. As for this paper, the IEEE Std. 519-2014 for voltage and current distortion depicted in the Table 2 and Table 3 was used as a reference [11].

Table 2. Voltage distortion limits

\begin{tabular}{|c|c|c|}
\hline Bus voltage V at PCC & Individual harmonic (\%) & $\begin{array}{c}\text { Total harmonic distortion THD } \\
(\%)\end{array}$ \\
\hline $\mathrm{V} \leq 1.0 \mathrm{kV}$ & 5.0 & 8.0 \\
\hline $1 \mathrm{kV}<\mathrm{V} \leq 69 \mathrm{kV}$ & 3.0 & 5.0 \\
\hline $69 \mathrm{kV}<\mathrm{V} \leq 161 \mathrm{kV}$ & 1.5 & 2.5 \\
\hline $161 \mathrm{kV}<\mathrm{V}$ & 1.0 & $1.5^{a}$ \\
\hline
\end{tabular}

${ }^{a}$ High-voltage systems can have up to $2.0 \%$ THD where the cause is an HVDC terminal whose effects will have attenuated at points in the network where future users may be connected. [5]

Table 3. Current distortion limits for systems rated $120 \mathrm{~V}$ through $69 \mathrm{kV}$

\begin{tabular}{|c|c|c|c|c|c|c|}
\hline \multicolumn{7}{|c|}{$\begin{array}{c}\text { Maximum harmonic current distortion } \\
\text { in percent of } \boldsymbol{I}_{\mathrm{L}}\end{array}$} \\
\hline \multicolumn{7}{|c|}{ Individual harmonic order (odd harmonics) } \\
\hline$I_{\mathrm{SC}} / I_{\mathrm{L}}$ & $3 \leq h<11$ & $11 \leq h<17$ & $17 \leq h<23$ & $23 \leq h<35$ & $35 \leq h \leq 50$ & $\mathrm{TDD}$ \\
\hline$<20^{\mathrm{c}}$ & 4.0 & 2.0 & 1.5 & 0.6 & 0.3 & 5.0 \\
\hline $20<50$ & 7.0 & 3.5 & 2.5 & 1.0 & 0.5 & 8.0 \\
\hline $50<100$ & 10.0 & 4.5 & 4.0 & 1.5 & 0.7 & 12.0 \\
\hline $100<1000$ & 12.0 & 5.5 & 5.0 & 2.0 & 1.0 & 15.0 \\
\hline$>1000$ & 15.0 & 7.0 & 6.0 & 2.5 & 1.4 & 20.0 \\
\hline
\end{tabular}

${ }^{a}$ Even harmonics are limited to $25 \%$ of the odd harmonic limits above.

${ }^{\mathrm{b}}$ Current distortions that result in a dc offset, e.g., half-wave converters, are not allowed. Where,

cAll power generation equipment is limited to these values of current distortion, regardless of actual Isc/IL.

Isc = maximum short-circuit current at PCC

$\mathrm{IL}=$ maximum demand load current (fundamental frequency component) at the PCC under normal load operating conditions [7]. 


\subsection{Flowchart of research work}

Finally, the flowchart below has shown the sequential steps in order to get the output results for this case study.

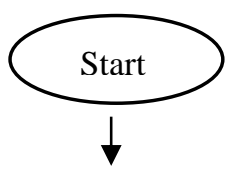

Select on which IEEE test systems of distribution network configuration and components to be used

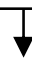

Inject the harmonic current spectrum from commercial building to the test system
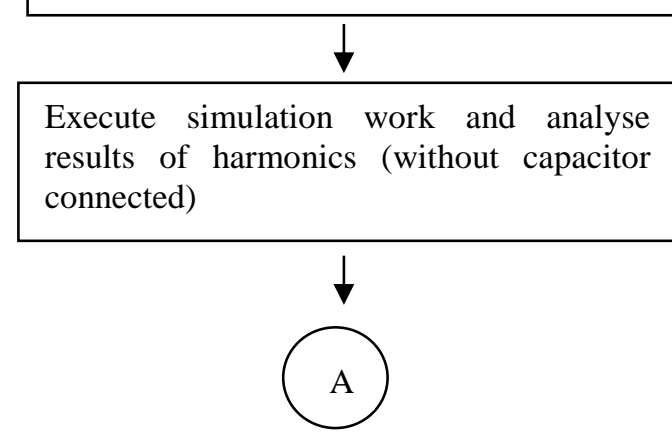

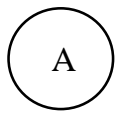

$\downarrow$

Set up the parameters for distribution capacitors and activate the operation of both capacitors in the test system

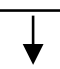

Execute simulation work and analyse result of harmonics (with capacitor connected)

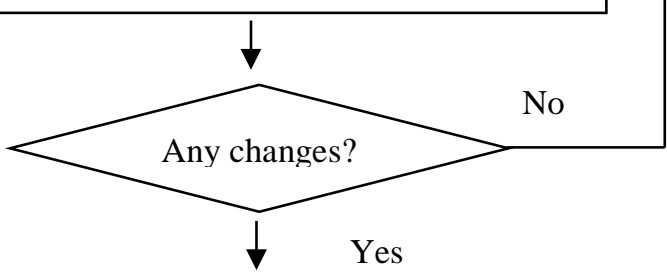

Compare and analyse the simulation of THD results

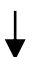

Calculate the resonance frequency and harmonic order

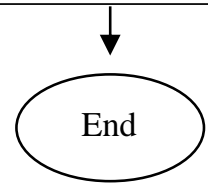

Figure 2: Flow chart of research work

\subsection{RESULTS AND DISCUSSION}

\subsection{Power factor correction}

As in the introduction part, one of the main functions of capacitor banks applied to the network system were to improve the power factor of the system. Hence, in this case study, Table 4 showed the value of the improved power factor when the capacitor banks operated at both 611 node bus and 675 node bus.

Table 4. The improved power factor at the node buses

\begin{tabular}{|c|c|c|}
\hline Node & Before power factor correction & After power factor correction \\
\hline $675 \mathrm{a}$ & 0.93 & No need to be corrected \\
\hline $675 \mathrm{~b}$ & 0.75 & 0.9 \\
\hline $675 \mathrm{c}$ & 0.81 & 0.9 \\
\hline 611 & 0.43 & 0.85 \\
\hline
\end{tabular}




\subsection{Total harmonic distortion}

On the other hand, despite the benefit of the capacitor banks that has improved the power factor, the resonance effect has started to give impact on the total harmonic distortion. This can be best observed throughout the plotted THDi and THDV graphs in Figure 3 until Figure 6 which showed the comparison of the THD level before and after the capacitor banks being connected to the selected node buses. The analysis was focused on two monitored lines which were between 684 and 611 node bus, marked as line 684611 and also between 692 and 675 node bus, marked as line 692675. All the output results were discussed more details in the next subsection with clearer numeric figures in provided tables.

As for the harmonic current distortion, Figure 3 until Figure 4 showed the percentage of THDi for both monitored lines, before and after the capacitor banks being connected to the network system. It can be observed that the injection of the harmonic current spectrums has already caused the both line 684611 and line 692675 to violate the standard limit even right before the capacitor banks being activated into the system. Then by activated the operation of the capacitor banks, the distortion was transited to some value differently in each phases.

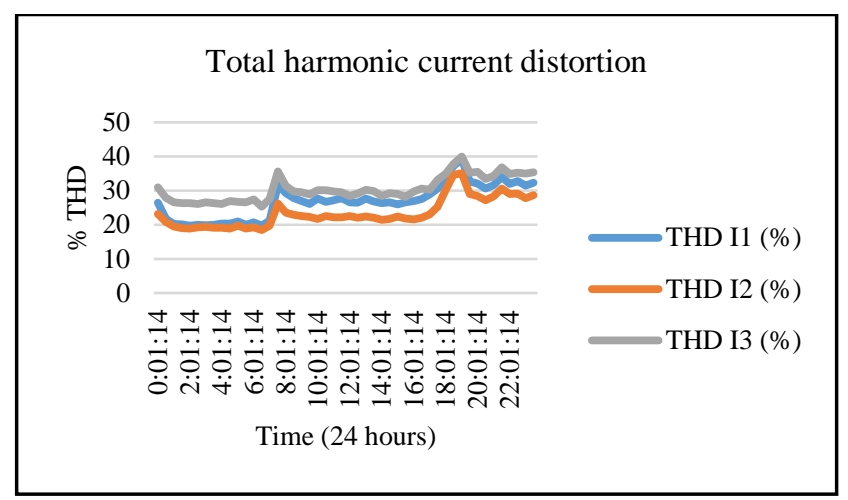

Figure 3. (a) THDi at line 692675 (without caps)

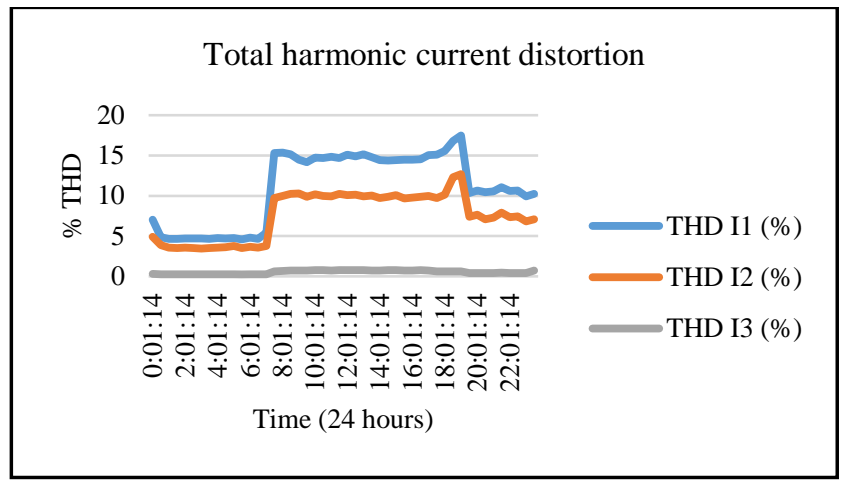

Figure 4. (a) THDi at line 684611 (without caps)

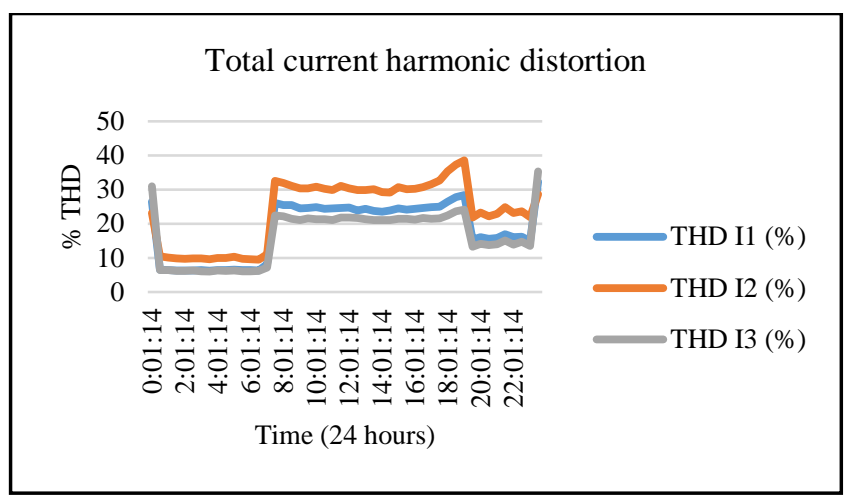

(b) THDi at line 692675 (with caps)

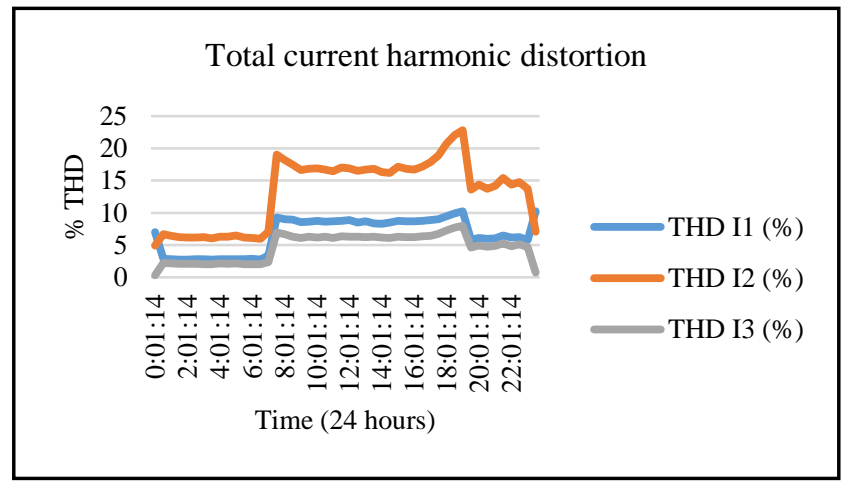

(b) THDi at line 684611 (with caps)

Meanwhile, Figure 5 until Figure 6 showed the simulation graph results of THDv for both monitored lines before and after the capacitor banks being connected to the network test system. From all figures, it clearly observed that harmonic voltage distortions were transited and magnified in all phases. 


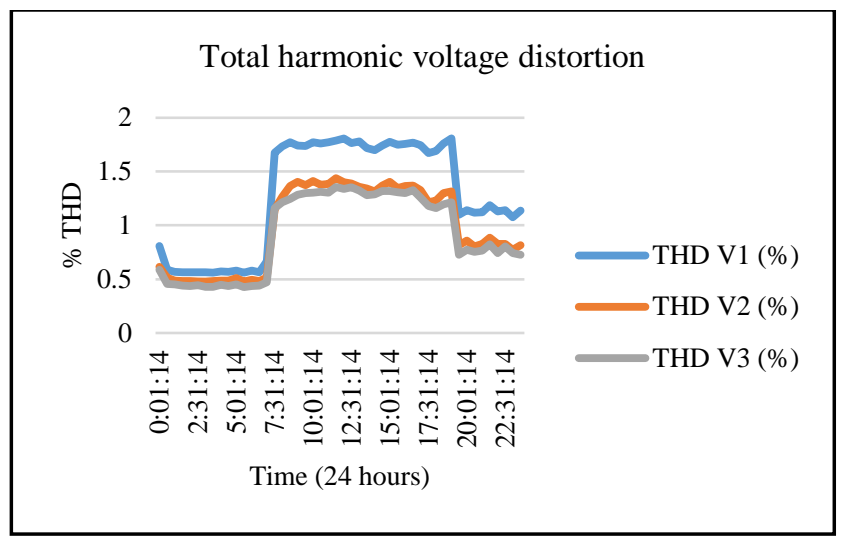

Figure 5. (a) THDv at line 692675 (without caps)

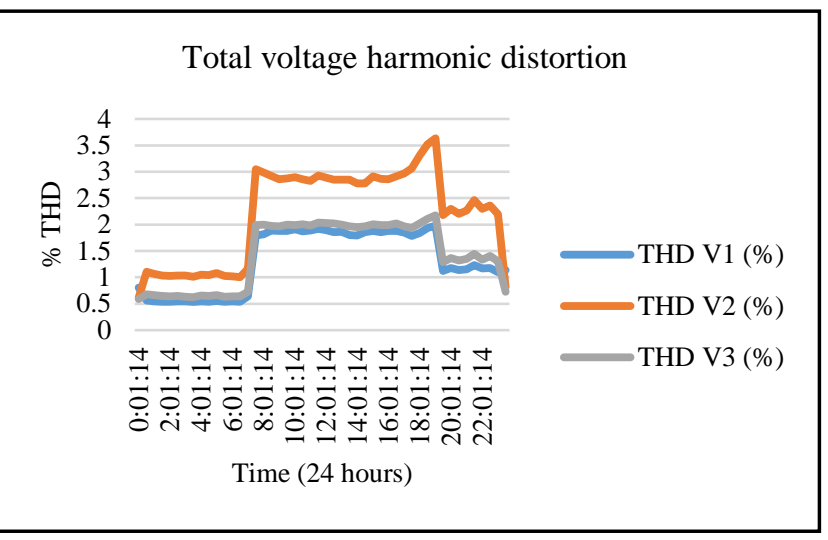

(b) THDv at line 692675 (with caps)

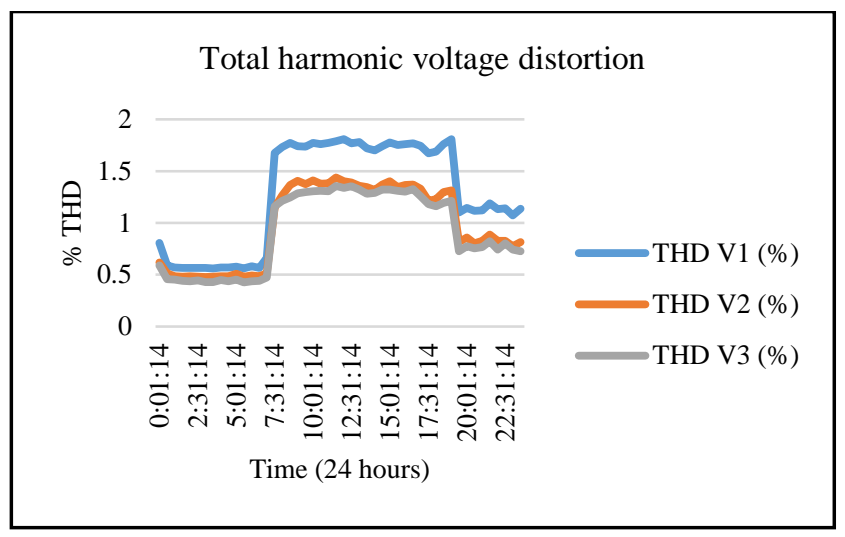

Figure 6. (a) THDv at line 684611 (without caps)

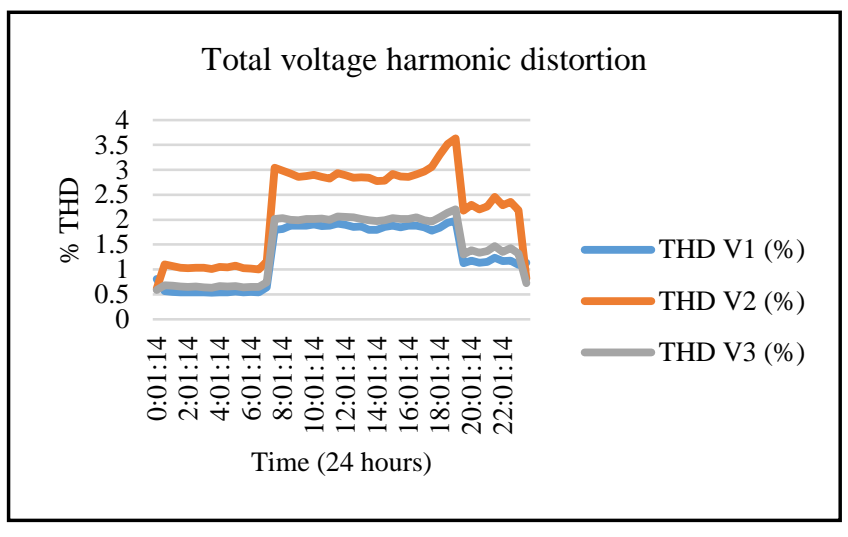

(b) THDv at line 684611 (with caps)

The simulation graphs result in above figures showed that the monitored lines were having significant differences in the THDi and THDv values, before and after the distribution capacitors being connected to the network system. The harmonics contents which were already existed in the network seem to be actively mushroomed and instantly increased the THDi (in certain phases) and THDv (in all phases).

The exact numeric figures to show the changes of the percentage THD value can be best observed in the Table 5 and Table 6 for both monitored lines. The transistion in THDi level from the Table 5 has revealed the effect of the resonance from the capacitors operation which has increased the THDi but only in certain phases. The highest increment was happened at second phase of line 684611 which was almost up to two times higher from its initial level. It must be noted that, with such high THD level, the overall network system could be seriously jeopardized. At this point, if the resonant is the same as the harmonic component, unpredicted burn out of the system's equipment or devices may occur due to the amplified harmonic current [12].

An improvement in the future work should be done in order to analyse the nonuniformity increment in the THDi. As for this case study, the assumption for the nonunifomity was due to the value of impedance from load and supply in between the lines has somehow caused the THD to decreased [14]. This condition is actually can determine the responsibility of the excessive THD either it is the utility side or the customer side, but it will not be discussed in this paper.

Table 5. The percentage of THDi without and with distribution capacitors

\begin{tabular}{|c|c|c|}
\hline Monitored line & $\begin{array}{c}\text { Percentage of THDi ( without } \\
\text { caps) }\end{array}$ & Percentage THDi (with caps) \\
\hline 684611 & $i_{1}=17.4800 \%$ & $i_{1}=10.2508 \%$ \\
& $i_{2}=12.6835 \%$ & $i_{2}=22.8175 \%$ \\
& $i_{3}=0.7174 \%$ & $i_{3}=7.9802 \%$ \\
\hline 692675 & $i_{1}=39.2775 \%$ & $i_{1}=32.2898 \%$ \\
& $i_{2}=35.0859 \%$ & $i_{2}=38.5694 \%$ \\
& $i_{3}=39.9679 \%$ & $i_{3}=35.3215 \%$ \\
\hline
\end{tabular}


The THDv on the other hand, the changes in the increment of distortion percentage values were experienced by all phases. But the percentage values of the THDv were seem not too high and still under compliance of $5 \%$ for the $2.4 \mathrm{kV}$ distribution system standard. But despite to that, it must be taken into precaution action as to avoid the unwanted even such as sudden breakdown or failure which could brought into huge loss in the network system.

Table 6. The percentage of THDv without and with distribution capacitors

\begin{tabular}{|c|c|c|}
\hline Monitored line & $\begin{array}{c}\text { Percentage of THDv (without } \\
\text { caps) }\end{array}$ & Percentage THDv (with caps) \\
\hline 684611 & $v_{1}=1.8065 \%$ & $v_{1}=1.9769 \%$ \\
& $v_{2}=1.4352 \%$ & $v_{2}=3.6327 \%$ \\
& $v_{3}=1.3557 \%$ & $v_{3}=3.2079 \%$ \\
\hline 692675 & $v_{1}=1.8084 \%$ & $v_{1}=1.9786 \%$ \\
& $v_{2}=1.4386 \%$ & $v_{2}=3.6330 \%$ \\
& $v_{3}=1.3565 \%$ & $v_{3}=2.1742 \%$ \\
\hline
\end{tabular}

Other than that, it is important to determine which harmonic order when all the excessive THD occurred. This is because they will indicate either it could jeopardize the network system or not. Theoretically, only odd harmonic order could harm the system and shall not be worried if the resonance occurred during aneven harmonic order. Based on the harmonic order acquired from the resonance frequency for this research work, the results obtained which illustrated in the Table 7 below shall not be much concerned because they were not in significant odd order. But still, it can be said that the resonance frequency from the capacitor banks did played a very important role in harmonic and distortion occurrence.

Table 7. The resonance frequency and harmonic order at each node buses

\begin{tabular}{|c|c|c|}
\hline Node & Resonance frequency, fr & Harmonic order, $\mathbf{H}$ \\
\hline $675 \mathrm{a}$ & $100.75 \mathrm{~Hz}$ & $1.42 \approx 1$ \\
\hline $675 \mathrm{~b}$ & $54.23 \mathrm{~Hz}$ & $1.08 \approx 1$ \\
\hline $675 \mathrm{c}$ & $58.94 \mathrm{~Hz}$ & $1.18 \approx 1$ \\
\hline 611 & $79.47 \mathrm{~Hz}$ & $1.59 \approx 2$ \\
\hline
\end{tabular}

\subsection{CONCLUSION}

In a conclusion, the hypothesis that the operation of the capacitor banks could give impact to the level of THD was clearly proven. In this case study, the real data of harmonic current injection from the commercial site has increased the existed THD at the monitored lines up to two times from the original reading and this could be hazardous to the network system. Anyhow, the case study in this paper showed that the THD increment still could not affect the stability of the network system as it happened on insignificant harmonic order, but it is still must be put into precaution zone in order to avoid the unexpected failure that can cause massive loss for the network. Hence, a proper monitoring and maintenance system shoud be provided and perhaps it will continuously benefit all related parties either from supply or from the loads.

\section{Acknowledgements}

The authors would like to express the appreciation to the Ministry of Education Malaysia (MOE), the support of the sponsors [Vot Number = Q. J130000.2423.03G88] and also to the Universiti Teknologi Malaysia (UTM) for providing the best education and research facilities in order for to achieve the aims and goals in research studies and works.

\section{References}

[1] G. Das et al., 2010. Effects of Capacitor Bank Defects on Harmonic Distortion and Park's Pattern Analysis in Induction Motors. International Journal of Electrical, Computer, Energetic, Electronic and Communication Engineering Vol: 4, No:2, 2010.

[2] N. G. Gagaoudakis and A. D. Georopoulos, 1998. Investigation of Harmonic in Relation to 150kV Capacitor Banks at PPC's Philippi Substation. International Conference on Harmonic and Quality of Power ICHQP.

[3] Meisam Sadeghi et al., 2011. Mitigation of Capacitor Banks Switching Transients Considering Injected Harmonics. 
[4] Joel Elmore, March 2016. Power Factor Correction and Harmonics: How PFC Capacitors Affect Harmonic Levels.

[5] John Ware. 2006. Power Factor Correction (pfc) IEE Wiring Matters. 2006 IET Spring issues.

[6] Yu Cui and Wilsun Xu. 2007. Assessment of Potential Harmonic Problems for Systems with Distributed or Random Harmonic Sources. IEEE Power Engineering Society General Meeting. 10.1109/PES.2007.385447.

[7] V.J. Gosbell et al. 2000. Harmonic Distortion in Electric Supply System. Technical Note No.3.

[8] Gül, Ö. and Gündoğdu, T. 2015. Harmonic Contributions of Utility and Customer Based on Load Model Using Field Measurements. Journal of Power and Energy Engineering, 3, 11-28.

[9] Thomas E. Grebe. 1996. Application of Distribution System Capacitor Banks and Their Impact on Power Quality. IEEE Transactions on Industry Applications. Vol. 32. No. 3.

[10] S. J. Bester and G. Atkinson-Hope. 2011. Power Engineering Conference (AUPEC): Harmonic Filter Design to Mitigate Two Resonant Points in a Distribution Network.

[11] IEEE Std 519-2014, IEEE Recommended Practice and Requirements for Harmonic Control in Electric Power Systems.

[12] Ting-Yen Hsieh et al. 2012. Assessment of Effects of Capacitor Banks on Harmonic Distortion by a Direct Z-bus Power Flow Method. 2012 10th International Power \& Energy Conference (IPEC). 10.1109/ASSCC.2012.6523293

[13] B. Sreewirote, and A. Ngaopitakkul. 2016. Analysis of Power Quality Issue in Arc Furnace Capacitor Bank System. 2016 19th International Conference on Electrical Machines and Systems (ICEMS).

[14] J. C. Das. 2012. Textbook of Power System Analysis; Short-Circuit Load Flow and Harmonics, Second Edition.

[15] J. Arrillaga and R. Watson. 2004. Textbook of Power System Harmonics, Second Edition. 